\title{
Proflavin suppresses the growth of human osteosarcoma MG63 cells through apoptosis and autophagy
}

\author{
MAO-SHU ZHANG ${ }^{1}$, FU-WEN NIU ${ }^{1}$ and $\mathrm{KUN} \mathrm{LI}^{2,3}$ \\ ${ }^{1}$ Department of Orthopaedics, Jining No. 1 People's Hospital, Jining, Shandong 272011; \\ ${ }^{2}$ Department of Gynaecology and Obstetrics, Affiliated Hospital of Shandong Academy of Medical Sciences; \\ ${ }^{3}$ Department of Gynaecology and Obstetrics, Shandong Academy of Medical Sciences, Jinan, Shandong 250062, P.R. China
}

Received July 22, 2014; Accepted April 14, 2015

DOI: $10.3892 / 01.2015 .3206$

\begin{abstract}
Proflavin is one of the novel acridine derivatives that possess various pharmacological effects. Although numerous studies have been performed to investigate proflavin, its effects have not been investigated on the human osteosarcoma MG63 cell line. The core aim of the present study was to test the effects of proflavin on the viability of MG63 cells and the induction of apoptosis and autophagy in MG63 cells. The induction of apoptosis was examined by measuring the changes in the expression of the B-cell lymphoma 2 (Bcl-2) and $\mathrm{Bcl}-2$-associated $\mathrm{X}$ protein mRNA and proteins. Apoptotic cell death was identified by the proteolytic cleavage of poly (adenosine diphosphate-ribose) polymerase and caspase-3 and caspase-9. In addition, the autophagic effects of proflavin were examined by the quantitation of the mRNA expression of autophagy protein 5 and Beclin 1, in addition to the identification of the accumulation of microtubule-associated protein 1 light chain 3 -II. The present results revealed that proflavin inhibited the proliferation of MG63 cells in a dose-dependent manner. Proflavin-induced cell death was attributed to apoptosis and autophagy. Overall, the present results indicated that the antiseptic agent proflavin exerts anticancer potential through the synergistic activity of apoptosis and autophagy.
\end{abstract}

\section{Introduction}

Osteosarcoma is one of the most common childhood malignancies, with 400 novel cases of osteosarcoma diagnosed in the USA each year (1). Pathologically, osteosarcoma arises from mesenchymal cells, which are characterized by spindle cells and aberrant osteoid formation. The primary sites of osteosarcoma are typically the distal femur, the proximal tibia

Correspondence to: Dr Fu-Wen Niu, Department of Orthopaedics, Jining No. 1 People's Hospital, 6 Jiankang Road, Jining, Shandong 272011, P.R. China

E-mail: niufuwen39@hotmail.com

Key words: proflavin, MG63 cells, apoptosis, autophagy and the distal humerus, with $64 \%$ of lesions arising from the knee (2). The administration of neoadjuvant chemotherapy and surgical intervention has increased the five-year survival rate from $\sim 10 \%$ to $70 \%$ in the last 30 years (3). Despite the additional improvements in the treatment of osteosarcoma over the previous 20 years, the overall survival rate of patients has reached a plateau (4). In osteosarcoma, a poor response to chemotherapy is associated with a poorer outcome and a lower survival rate (5). However, it has been demonstrated that an increase in drug efflux, a decrease drug influx, inactivation of the agent, alterations in the drug targets, increased DNA damage repair and evasion of apoptosis all contribute to intrinsic or acquired tumor chemoresistance (6). In modern treatment regimens, various chemotherapeutic agents are administered in combination, either intravenously or orally, pre- and post-operatively (7-9). However, the majority of chemotherapeutic agents also carry the risk of short- and long-term toxic and adverse effects (10). Therefore, identification of the effector molecules and signal transduction pathways that are responsible for the regulation of carcinogenesis and malignant development is vital to understand and isolate potential molecular targets that may be used to disrupt the tumor machinery, whilst protecting the integrity and function of normal tissue.

The acridine family is extensive (11) and includes a wide variety of nitro, halo, hydroxy, cyano, alkyl and aryl derivatives. The chemotherapeutic action of acridines is their most notable property. In particular, the 3,6-diaminoacridine dye proflavin is also an acridine derivative. Acridine derivatives were initially developed as dyes, and during the early 20th century, the pharmacological properties of the derivatives were evaluated. During this time, proflavin was used as a topical antibacterial and antifungal agent. This acridine derivative is well known for its disinfectant bacteriostatic properties against numerous gram-positive bacteria. Proflavin is used as a topical antiseptic in the form of dihydrochloride and hemisuphate salts, and was formerly used as a urinary antiseptic. The roles of proflavin as a mutagen and as an enzyme inhibitor have been extensively studied $(12,13)$. Proflavin has been used as a mitotic inhibitor that interferes with nucleic acid synthesis in vivo $(14,15)$ and in vitro, and it also acts as a potent mutagen (16) that intercalates itself between adjacent base pairs of the DNA molecule, causing 
deletion errors during replication (17). These effects are of interest for the study of genic action. Proflavin was included in a systematic investigation into the action of various types of antimetabolites on nucleolar fine structure. The lesions produced by proflavin in the nucleus and the nucleolus were identified to be so specific that this compound received particular attention (18). However, to the best of our knowledge, no studies have been performed on the action of proflavin against osteosarcoma at present. Therefore, the present study aimed to determine the effects of proflavin on osteosarcoma cells and to predict the underlying mechanism with emphasis on anticancer activity. The present study hypothesized that proflavin exerts anticancer activity in osteosarcoma with involvement of apoptosis and autophagy. The human osteosarcoma MG-63 cell line was used to explore the anticancer property of proflavin and changes in cell viability with focuses on apoptosis and autophagy was also assessed by real-time PCR and immunoblotting methods.

\section{Materials and methods}

Materials. The human osteosarcoma MG63 cell line (catalog no., CRL-1427) was obtained from the American Type Culture Collection (Manassas, VA, USA) and maintained in Dulbecco's modified Eagle's medium (DMEM) supplemented with $10 \%$ fetal bovine serum (FBS) and $100 \mu \mathrm{g} / \mathrm{ml}$ penicillin/streptomycin at $37^{\circ} \mathrm{C}$ in a humidified atmosphere containing $5 \%$ $\mathrm{CO}_{2}$. DMEM, FBS and trypsin-EDTA were purchased from Gibco Life Technologies (Gaithersburg, MD, USA). Proflavin, penicillin, streptomycin and dimethyl sulfoxide (DMSO) were purchased from Sigma-Aldrich (St. Louis, MO, USA). Antibodies against caspase-3 (polyclonal rabbit anti-human; catalog no. 9662), caspase-9 (polyclonal rabbit anti-human; catalog no. 9502), B-cell lymphoma 2 (Bcl-2; polyclonal rabbit anti-human; catalog no. 2872), Bcl-2-associated $X$ protein (Bax; polyclonal rabbit anti-human; catalog no. 2774), light chain 3 (LC3)-I (monoclonal rabbit anti-human; catalog no. 4599), LC3-II (monoclonal rabbit anti-human; catalog no. 4599), poly(adenosine diphosphate-ribose) polymerase (PARP; monoclonal rabbit anti-human; catalog no. 9532) and $\beta$-actin (polyclonal rabbit anti-human; catalog no. 4967) were purchased from Cell Signaling Technology, Inc. (Danvers, MA, USA). Horseradish peroxidase-conjugated secondary antibodies against mouse immunoglobulin G ( $\mathrm{IgG}$ ) (polyclonal rabbit; catalog no. ab6728) and rabbit IgG (polyclonal goat; catalog no. ab6721) were purchased from Abcam (Cambridge, MA, USA).

Cell culture and MTT assay. The cells were seeded in six-well culture plates at an initial density of $1 \times 10^{5}$ cells $/ \mathrm{ml}$ and grown to $\sim 80 \%$ confluence. For experimental treatments, the cells were administered with proflavin at concentrations of $0,0.1$, 1, 5 and $10 \mu \mathrm{M}$ in serum-free DMEM for $24 \mathrm{~h}$. Following treatment, the cells were washed with phosphate-buffered saline (PBS) that contained $25 \mathrm{mM}$ sodium phosphate and $150 \mathrm{mM} \mathrm{NaCl}$ ( $\mathrm{pH}$ 7.2), and were harvested for the subsequent analyses.

An MTT assay was performed to determine cell viability. The cells were seeded overnight in 96-well plates at a density of $1 \times 10^{4}$ cells/well prior to treatment. Following treatment, the medium was replaced with $0.5 \mathrm{mg} / \mathrm{ml}$ MTT solution. The supernatant was removed after $3 \mathrm{~h}$ of incubation at $37^{\circ} \mathrm{C}$ and DMSO was subsequently added. Absorbance was measured at $540 \mathrm{~nm}$, with background subtraction at $650 \mathrm{~nm}$, on EMax Endpoint ELISA Microplate Reader (Molecular Devices LLC, Sunnyvale, CA, USA). Percentage survival was defined as: Survival $(\%)=100 \times\left(\mathrm{T}-\mathrm{T}_{0}\right) /\left(\mathrm{C}-\mathrm{T}_{0}\right)$, when $\left(\mathrm{T}-\mathrm{T}_{0}\right)=0$. When $\mathrm{T}<\mathrm{T}_{0}$, cell death had occurred and the cytotoxic activity was determined as follows: Cytotoxic activity $(\%)=\left(\mathrm{T}-\mathrm{T}_{0}\right) / \mathrm{T}_{0}$, where $\mathrm{T}$ is the optical density $(\mathrm{OD})_{540}$ value at the time-point in question, and $\mathrm{T}_{0}$ is the $\mathrm{OD}_{540}$ value at the moment of drug administration. $\mathrm{C}$ indicates the $\mathrm{OD}_{540}$ value of the untreated control group at the time-point in question. $\mathrm{IC}_{50}$ values were calculated from three independent experiments.

Reverse transcription-quantitative polymerase chain reaction $(R T-q P C R)$. Following treatment in the present study, total RNA was extracted using TRIzol reagent (Ambion Life Technologies, Carlsbad, CA, USA). The quantity of RNA was determined using the Qubit RNA Assay kit (Invitrogen, Carlsbad, CA, USA). Reverse transcription was performed in a 20- $\mu 1$ reaction with $200 \mathrm{ng}$ total RNA using high-capacity cDNA reverse transcription kits (Applied Biosystems Life Technologies, Foster City, CA, USA). Relative quantification of apoptosis and autophagy markers were assessed using the ABI 7900 HT system (Applied Biosystems Life Technologies). The housekeeping gene GAPDH was used as an internal control. The primer sequences used are reported in Table I.

Immunoblotting. Subsequent to treatment with proflavin, the cells were washed with PBS and incubated with RIPA buffer (Sigma-Aldrich) on ice for $5 \mathrm{~min}$. The resulting samples were then centrifuged at $23,800 \times \mathrm{g}$ for $15 \mathrm{~min}$ at $4^{\circ} \mathrm{C}$. The supernatants were collected for the subsequent western blotting. The protein concentration was measured using Qubit Protein Assay kit. Equal amounts of cellular protein $(20 \mu \mathrm{g} / \mathrm{sample})$ were electrophoresed using $12 \%$ SDS-PAGE and the gels were then transferred to polyvinylidene difluoride membranes (Amersham Pharmacia Biotech, Zurich, Switzerland) at $100 \mathrm{~V}$ for $1 \mathrm{~h}$ at $4^{\circ} \mathrm{C}$. The blots were incubated with $5 \%$ bovine serum albulmin in Tris-buffered saline in Tween-20 (TBST; Sigma-Aldrich). The membranes were incubated with a 1:1,000 dilution of antibodies against caspase-9, caspase-3, PARP and $\beta$-actin for $1 \mathrm{~h}$ at room temperature. The blots were washed with TBST and incubated with secondary antibody (dilution, 1:2,000) for $30 \mathrm{~min}$ at room temperature. For signal detection, the blots were then incubated with peroxidase-coupled goat anti-rabbit immunoglobulin (Amersham Pharmacia Biotech) and the enhanced chemiluminescence (Amersham Pharmacia Biotech) reagents were used to detect the signals, according to the manufacturer's instructions.

Statistical analysis. The data were expressed as the mean \pm standard error of the mean of the three independent experiments. The statistical significance of differences was determined using one-way analysis of variance followed by Dunnett's test for multiple comparisons with the control. 
Table I. Primers used in reverse transcription-quantitative polymerase chain reaction.

\begin{tabular}{lll}
\hline Gene & \multicolumn{1}{c}{ Forward primer } & \multicolumn{1}{c}{ Reverse primer } \\
\hline Bax & TGGAGCTGCAGAGGATGATTG & GGCCTTGAGCACCAGTTTG \\
Bcl-2 & GCTATAACTGGAGAGTGCTGAAGATTG & TGATGTTGTATTTTTAAGTACAGCATGAT \\
Atg5 & ATGGACAGTTGCACACACTAGGA & ATCTTCAGGATCAATAGCAGAAGGA \\
Beclin 1 & CTCACAGCTCCATTACTTACCACAG & TCAATAAATGGCTCCTCTCCTGA \\
GAPDH & AATGGAAATCCCATCACCATCT & CAGCATCGCCCCACTTG \\
\hline
\end{tabular}
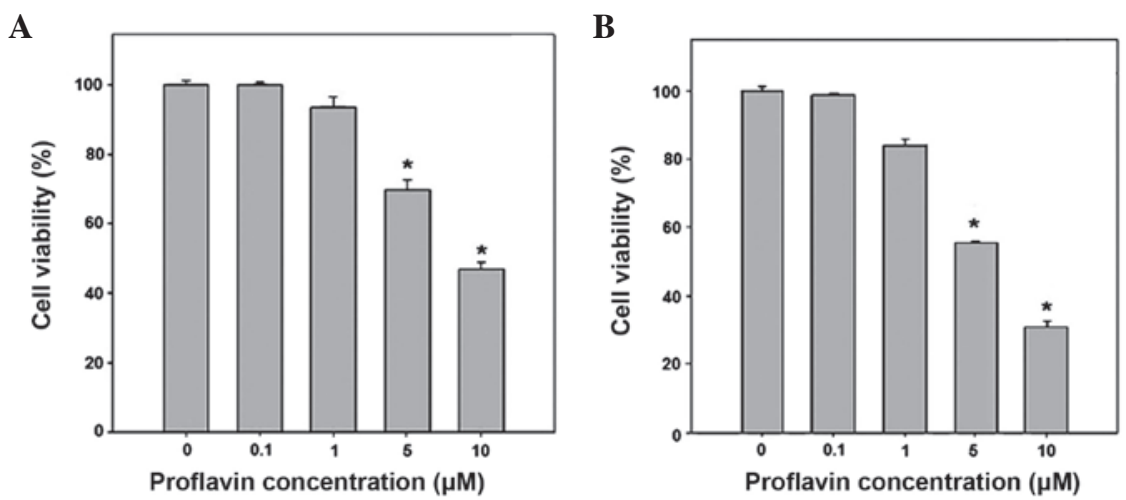

Figure 1. Effect of proflavin on the growth of osteosarcoma MG-63 cells. MG-63 cells were treated with proflavin for (A) $24 \mathrm{~h}$ and (B) $48 \mathrm{~h}$. Cell viability was determined by an MTT assay. The experiments were performed in triplicate, and the data were expressed as the mean \pm standard deviation. "P<0.05 vs. $0 \mu \mathrm{M}$ proflavin.

$\mathrm{P}<0.05$ was considered to indicate a statistically significant difference.

\section{Results}

Proflavin inhibition of osteosarcoma MG-63 cells. An MTT assay determined the inhibitory effect of proflavin on the growth of MG63 osteosarcoma cells. In the MTT assay, the MG-63 osteosarcoma cells were treated with proflavin at concentrations of $0,0.1,1,5$ and $10 \mu \mathrm{M}$ for 24 or $48 \mathrm{~h}$, which was followed by viability analysis. As shown in Fig. 1, the treatment of the MG-63 cells with $0-10 \mu \mathrm{M}$ proflavin resulted in the suppression of cell growth in a dose-dependent manner. The viability was significantly decreased to $68.7 \pm 3.0$ and $47.7 \pm 1.5 \%$ of the viability of the control cells in response to treatment with 5 and $10 \mu \mathrm{M}$ of proflavin for $24 \mathrm{~h}$, respectively $(\mathrm{P}<0.05$ vs. control). The prolonged treatment with proflavin led to a greater inhibition of cell viability, which was $54.8 \pm 0.4$ and $32.1 \pm 1.5 \%$ of control with 5 and $10 \mu \mathrm{M}$ of proflavin, respectively ( $\mathrm{P}<0.01$ vs. control).

Apoptosis studies. Apoptosis assays were performed to elucidate the mechanisms underlying proflavin-induced growth inhibition on MG-63 cells treated with proflavin at various concentrations. The present study identified that the induction of apoptosis was based on the alteration of apoptotic biomarkers in proflavin-treated MG-63 cells. From the results shown in Fig. 2A, a significant decrease in the level of procaspase- 3 was observed to be in association with increased cleaved caspase- 3 levels at concentrations of 5 and $10 \mu \mathrm{M}$ compared with the controls. The results also revealed that proflavin induced an increase in cleaved caspase-9 levels in a dose-dependent manner and proflavin treatment at $10 \mu \mathrm{M}$ led to significant cleavages of PARP in MG63 cells. In addition, the effect of proflavin treatment on the expression of apoptotic genes was investigated using RT-qPCR and western blotting. As shown in Fig. 2B, the ratio of Bax to Bcl-2 mRNA was significantly elevated in the cells treated with proflavin at higher concentrations compared with the controls. In addition, the response to the alteration in protein levels of Bax and Bcl-2 in MG-63 cells treated with proflavin was identified and is shown in Fig. 2C.

Proflavin induced autophagy. Autophagy plays an important role in protecting against cancer, and potentially in contributing to the growth of cancer (19). Autophagy may protect against cancer by isolating damaged organelles, allowing cell differentiation, increasing protein catabolism and even promoting cell death in cancerous cells (20). However, autophagy also contributes to cancer by promoting the survival of tumor cells that have been starved. The role of autophagy in cancer is one that has been highly investigated and reviewed. There is evidence that emphasizes the role of autophagy as a tumor suppressor and a factor in tumor cell survival. However, previous studies have been able to demonstrate that autophagy is more likely to be used as a tumor suppressor, according to several models $(19,20)$.

The role of autophagy in proflavin-induced cell death was then investigated in osteosarcoma cells. The results revealed that autophagy contributed to cell death in the presence of drug treatment against osteosarcoma cells. The experimental data revealed that exposure to 5 and $10 \mu \mathrm{M}$ proflavin led 
A

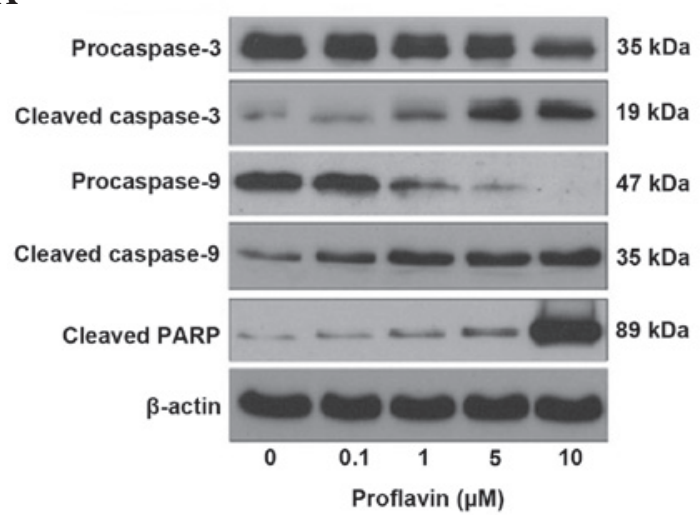

B

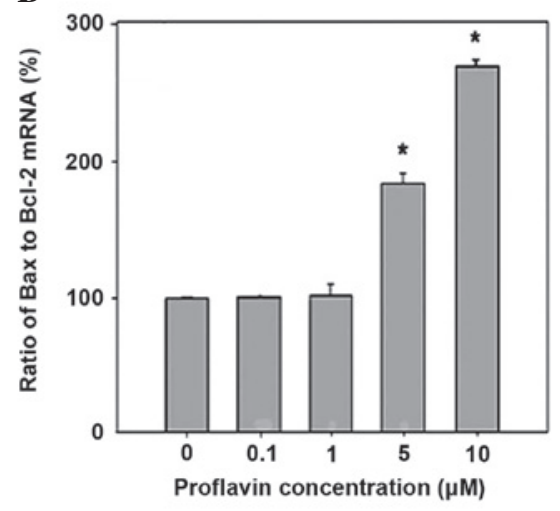

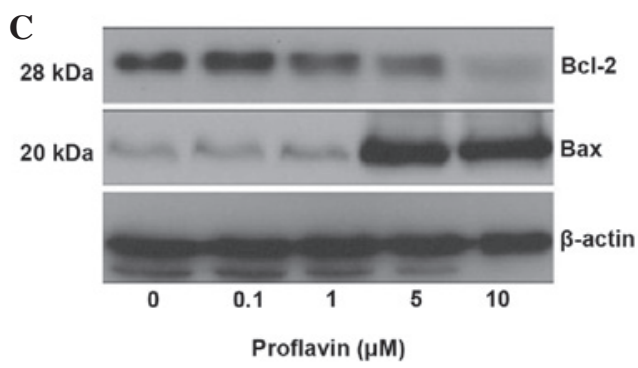

Figure 2. Proflavin induced apoptosis in osteosarcoma MG-63 cells. MG-63 cells were treated with proflavin for 24 h. Subsequent to treatment, total protein was extracted from proflavin-treated MG-63 cells to perform western blot analysis. Antibodies against procaspase-3, caspase-3, procaspase-9, caspase-9 and PARP were used to measure the expression level of these apoptosis-associated proteins. (A) Total RNA was extracted and cDNA was reverse-transcribed from mRNA for quantitative polymerase chain reaction of Bax and Bcl-2. (B) Changes in the levels of expression of the Bax and Bcl-2 proteins were revealed using western blotting. (C) The experiments were performed in triplicate, and the data were expressed as the mean \pm standard deviation. "P $<0.05$ vs. $0 \mu \mathrm{M}$ proflavin. PARP, poly(adenosine diphosphate-ribose) polymerase; Bcl-2, B-cell lymphoma 2; Bax, Bcl-2-associated X protein.

A

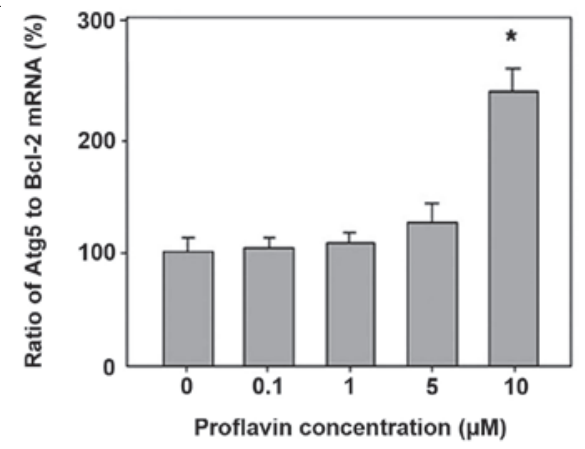

B

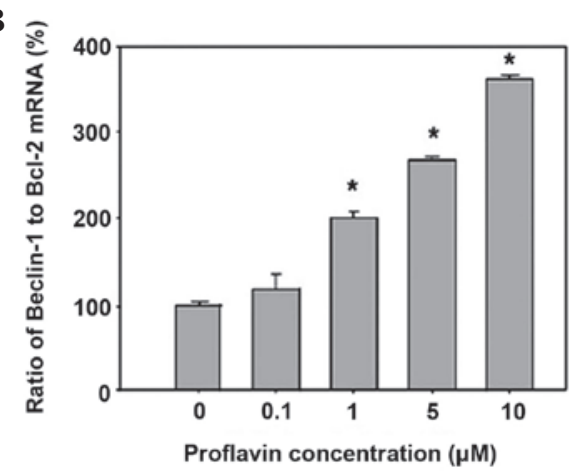

C

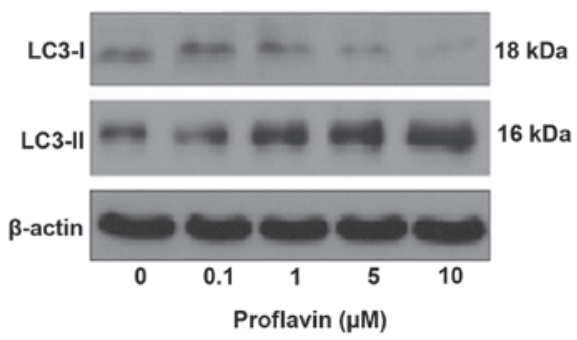

Figure 3. Treatment with proflavin at various concentrations for $24 \mathrm{~h}$ induced autophagy in osteosarcoma MG-63 cells. Subsequent to treatment, total RNA was extracted and cDNA was reverse transcribed from mRNA for quantitative polymerase chain reaction of (A) Atg5 and (B) Beclin 1. (C) Western blotting results. Antibodies against LC3 were used to determine the level of autophagosome formation. Experiments were performed in triplicate, and the data were expressed as the mean \pm standard deviation. ${ }^{*} \mathrm{P}<0.05$ vs. $0 \mu \mathrm{M}$ proflavin. LC3, light chain 3; Atg5, autophagy related 5; Bcl-2, B-cell lymphoma 2.

to an elevated autophagy related 5 (Atg5) to Bcl-2 mRNA ratio, up to a 1.2- and 2.4-fold increase compared with the ratio in the control and MG-63 cells, respectively. The ratio of the autophagy-associated genes Beclin 1 and Bcl-2 was also assessed in proflavin-treated MG-63 cells. The resulting data indicated that proflavin treatment increased the ratio 
of Beclin1 to Bcl-2 at concentrations of 5 and $10 \mu \mathrm{M}$ up to 2.5- and 3.5-fold compared to the ratio in control cells. Also, the influence of proflavin treatment on LC3-I and LC3-II levels was examined by western blot analysis, and the results demonstrated that the levels of LC3-II were significantly increased, whereas the LC3-I levels was were decreased, with a concomitant increase in the concentration of proflavin administered to MG-63 cells (Fig. 3).

\section{Discussion}

Acridines are generally known for their antibacterial and antiseptic activity. Several studies have indicated that acridines possess properties that inhibit tumor growth and cancer cell proliferation (21-24). Acriflavine, an acridine derivative has previously been used as an imaging contrast agent due to the ability to pass through the cell membrane and strongly label acidic constituents $(25,26)$. In addition, the molecular mechanism of the anticancer activity of acriflavine appears to vary depending on the type and origin of cancer. However, the mechanism underlying the inhibitory effect of acriflavine in osteogenic sarcoma cells remains to be elucidated. Acriflavine has been reported to initiate the apoptosis pathways in eukaryotic cells (27), and the underlying mechanism remains unclear. In yeast cells, acriflavine induces apoptosis through the alteration of the mitochondrial membrane, which subsequently results in apoptosis (12). In mammalian cells, acriflavine has been demonstrated to induce apoptosis in association with radiotherapy through $\mathrm{p} 53$-dependent mitochondrial pathways and ER stress signals (24).

Proflavin induces a series of ultrastructural alterations in cultured rat embryonic cells. Non-specific cytoplasmic lesions include disorganization of the endoplasmic reticulum and large cytoplasmic inclusions with osmiophilic material and myelin figures (28), which is similar to the abnormalities described in HeLa cells treated with acridine orange and in liver and pancreatic acinar cells of rats fed with ethionine and azaserine (18). However, characteristic nuclear and nucleolar lesions, including clumping of the chromatin with unsticking from the nuclear membrane, disappearance of the nucleoplasmic matrix and segregation of nucleolar components, occur with increased duration and concentration of treatment (18). Two other antimetabolites, daunomycin and ethidium bromide, which are chemically dissimilar to proflavin, produce identical nuclear and nucleolar lesions to proflavin at adequate concentrations. Since proflavin, daunomycin and ethidium bromide form complexes with DNA by intercalation between base pairs, the nuclear and nucleolar lesions may represent the morphological expression for a specific molecular action $(18,28)$.

In the present study, novel evidence that proflavin directly inhibits growth and promotes apoptosis in osteosarcoma cells was provided. Proflavin was found to significantly induce apoptosis in MG-63 cells at concentrations $>5 \mu \mathrm{M}$. The present results demonstrated that exposure of osteosarcoma cells to proflavin leads to dose-dependent PARP cleavage and the catalytic activation of caspases-3 and -9. It was suggested in the current study that proflavin induced apoptosis of MG-63 cells through the activation of the intrinsic caspase pathway. Since the activation of caspase-9 and PARP cleavage implicated mitochondrial apoptosis, the ratio of Bcl-2 and Bax mRNA expression was examined in MG-63 cells treated with proflavin. Treatment of MG-63 with proflavin increased the $\mathrm{Bax} / \mathrm{Bcl}-2$ ratio, indicating that proflavin causes mitochondrial membrane disruption that leads to the initiation of mitochondrial apoptosis. Since proflavin passes through the cell membrane, proflavin-induced cell death is likely to involve the activation of intrinsic apoptosis through caspases-3 and -9 and mitochondrial dysfunction. The present study observed that proflavin significantly induced autophagy in a dose-dependent manner in MG-63 cells. The expression of Beclin 1 and Atg5 was significantly upregulated in response to proflavin treatment, suggesting that proflavin induced autophagy in MG-63 cells by activating the Beclin 1/Atg5 pathway, which may be considered as a marker reflecting autophagic activity. The LC3 protein is distributed ubiquitously in mammalian tissues, as well as in cultured cells. It is known that the level of LC3-I in cells is relatively stable and that LC3-II is more sensitive to immunoblotting compared to LC3-I (29). As autophagy occurs, LC3-I is conjugated to phosphatidyl ethanolamine to form LC3-II, while autophagosomes take up cytoplasmic components. In the present study, autophagy was also characterized by an accumulation of cleaved LC3-II and a decrease in the level of LC3-I. The accumulation of LC3-II indicated the formation of autophagosomes in the presence of proflavin. Similar to the trend of apoptosis, the significant autophagic effect demonstrated by proflavin was observed in the cells treated with relatively high $(10 \mu \mathrm{M})$ concentrations of proflavin. As Beclin 1, Atg5 and LC3-II were upregulated, it is implied that proflavin induces autophagy the HIF-1 $\alpha$-dependent and HIF-1 $\alpha$-independent pathways.

In conclusion, the present study demonstrated that proflavin arrested the growth of MG63 osteosarcoma cells through the activation of apoptotic cascades. Additionally, autophagy was revealed to synergistically contribute to the proflavin-inhibited growth of osteosarcoma cells. Additional studies are required to elucidate and explore the mechanism by which proflavin suppresses osteosarcoma cells in vivo.

\section{Acknowledgements}

The authors thank Natural Science Foundation of Shandong Province (grant no. ZR2009CL027), Fund of Science Star program of Technology bureau of Jinan city (grant no., 20100118) and Medical Found of Academy of Medical Sciences of Shandong Province (grant no., 201023) for the financial assistance.

\section{References}

1. Kaatsch P: Epidemiology of childhood cancer. Cancer Treat Rev 36: 277-285, 2010.

2. Bielack SS, Kempf-Bielack B, Delling G, Exner GU, Flege S, Helmke K, Kotz R, Salzer-Kuntschik M, Werner M, Winkelmann W, et al: Prognostic factors in high-grade osteosarcoma of the extremities or trunk: An analysis of 1,702 patients treated on neoadjuvant cooperative osteosarcoma study group protocols. J Clin Oncol 20: 776-790, 2002.

3. Longhi A, Errani C, De Paolis M, Mercuri M and Bacci G: Primary bone osteosarcoma in the pediatric age: State of the art. Cancer Treat Rev 32: 423-436, 2006. 
4. Lee JA, Kim MS, Kim DH, Lim JS, Yoo JY, Koh JS, Lee SY, Jeon DG and Park KD: Relative tumor burden predticts metastasis-free survival in pediatric osteosarcoma. Pediatr Blood Cancer 50: 195-200, 2008

5. Bacci G, Longhi A, Versari M, Mercuri M, Briccoli A and Picci A: Prognostic factors for osteosarcoma of the extremity treated with neoadjuvant chemotherapy: 15-year experience in 789 patients treated at a single institution. Cancer 106: 1154-1161, 2006.

6. O'Driscoll L: Mechanisms of drug sensitivity and resistance in cancer. Curr Cancer Drug Targets 9: 250-251, 2009.

7. Anninga JK, Gelderblom H, Fiocco M, Kroep JR, Taminiau AH, Hogendoorn PC and Egeler AM: Chemotherapeutic adjuvant treatment for osteosarcoma: Where do we stand? Eur J Cancer 47: $2431-2445,2011$

8. Luetke A, Meyers PA, Lewis I and Juergens H: Osteosarcoma treatment - where do we stand? A state of the art review. Cancer Treat Rev 40: 523-532, 2014.

9. McTiernan A, Jinks RC, Sydes MR, Uscinska B, Hook JM, van Glabbeke M, Bramwell V, Lewis IJ, Taminiau AH, Nooij MA et al: Presence of chemotherapy-induced toxicity predicts improved survival in patients with localised extremity osteosarcoma treated with doxorubicin and cisplatin: A report from the European osteosarcoma intergroup. Eur J Cancer 48: 703-712, 2012.

10. Janeway KA and Grier HE: Sequelae of osteosarcoma medical therapy: A review of rare acute toxicities and late effects. Lancet Oncol 11: 670-678, 2010.

11. Acheson RM (ed): Acridines. Interscience Publishers, New York, NY, pp10-90, 1973

12. Li HJ and Crothers DM: Relaxation studies of the proflavine-DNA complex: The kinetics of an intercalation reaction. J Mol Biol 39 461-477, 1969.

13. Faller LD and LaFond RE: Binding properties of oligomeric alpha-chymotrypsin. Biochemistry 10: 1033-1041, 1971.

14. Bubel HC and Wolff DA: Proflavine inhibition of vaccinia virus synthesis. J Bacteriol 89: 977-983, 1965.

15. Scholtissek C and Rott R: Binding of proflavine to deoxyribonucleic acid and ribonucleic acid and its biological significance. Nature 204: 39-43, 1964.

16. Orgel A and Brenner S: Mutagenesis of bacteriophage T4 by acridines. J Mol Biol 3: 762-768, 1961.

17. Lerman LS: Structural consideration in the interaction of DNA and acridines. J Mol Biol 3: 18-30, 1961.
18. Simard R: Specific nuclear and nucleolar ultrastructural lesions induced by proflavin and similarly acting antimetabolites in tissue culture. Cancer Res 26: 2316-2328, 1966.

19. Furuya N, Liang XH and Levin B: Autophagy and cancer. In Autophagy. Klionsky DJ (ed). Landes Bioscience, Georgetown, TX, pp244-253, 2004.

20. Mathew R, Karp CM, Beaudoin B, Vuong N, Chen G, Chen HY, Bray K, Reddy A, Bhanot G, Gelinas C, et al: Autophagy suppresses tumorigenesis through elimination of p62. Cell 137: 1062-1075, 2009.

21. Hassan S, Laryea D, Mahteme H, Felth J, Fryknäs M, Fayad W, Linder S, Rickardson L, Gullbo J, Graf W, et al: Novel activity of acriflavine against colorectal cancer tumor cells. Cancer Sci 102: 2206-2213, 2011.

22. Strese S, Fryknäs M, Larsson R and Gullbo J: Effects of hypoxia on human cancer cell line chemosensitivity. BMC Cancer 13: 331, 2013.

23. Wong CC, Zhang H, Gilkes DM, Chen J, Wei H, Chaturvedi P, Hubbi ME and Semenza GL: Inhibitors of hypoxia-inducible factor 1 block breast cancer metastatic niche formation and lung metastasis. J Mol Med (Berl) 90: 803-815, 2012.

24. Lim MJ, Ahn JY, Han Y, Yu CH, Kim MH, Lee SL, Lim DS and Song JY: Acriflavine enhances radiosensitivity of colon cancer cells through endoplasmic reticulum stress-mediated apoptosis. Int J Biochem Cell Biol 44: 1214-1222, 2012.

25. Polglase AL, McLaren WJ, Skinner SA, Kiesslich R, Neurath MF and Delaney PM: A fluorescence confocal endomicroscope for in vivo microscopy of the upper- and the lower-GI tract. Gastrointest Endosc 62: 686-695, 2005.

26. Kiesslich R, Goetz M, Vieth M, Galle PR and Neurath MF: Confocal laser endomicroscopy. Gastrointest Endosc Clin N Am 15: 715-731, 2005.

27. Keyhani E, Khavari-Nejad S, Keyhani J and Attar F: Acriflavine-mediated apoptosis and necrosis in yeast Candida utilis. Ann NY Acad Sci 1171: 284-291, 2009.

28. Simard R, Langelier, Mandeville NM and Royal A: Inhibitors as tools in elucidating the structure and function of the nucleus. In: The Cell Nucleus. Busch H (ed). Vol 3. Academic Press Inc., London, pp447-487, 1974.

29. Mizushima $\mathrm{N}$ and Yoshimori T: How to interpret LC3 immunoblotting. Autophagy 3: 542-545, 2007. 